\title{
Pancreatic beta cell function persists in many patients with chronic type 1 diabetes, but is not dramatically improved by prolonged immunosuppression and euglycaemia from a beta cell allograft
}

\author{
E. H. Liu • B. J. Digon III - B. Hirshberg • R. Chang • \\ B. J. Wood • Z. Neeman • A. Kam • R. A. Wesley • \\ S. M. Polly • R. M. Hofmann • K. I. Rother • \\ D. M. Harlan
}

Received: 23 November 2008 / Accepted: 19 February 2009 / Published online: 6 May 2009

(C) Springer-Verlag 2009

\begin{abstract}
Aims/hypothesis We measured serum C-peptide (at least $0.167 \mathrm{nmol} / \mathrm{l})$ in 54 of 141 (38\%) patients with chronic type 1 diabetes and sought factors that might differentiate those with detectable C-peptide from those without it. Finding no differences, and in view of the persistent anti-beta cell autoimmunity in such patients, we speculated that the immunosuppression (to weaken autoimmune attack) and euglycaemia accompanying
\end{abstract}

E. H. Liu, B. J. Digon III and B. Hirshberg contributed equally to this study.

E. H. Liu • B. J. Digon III • B. Hirshberg · K. I. Rother •

D. M. Harlan $(\bowtie)$

Diabetes Branch, National Institute of Diabetes,

and Digestive and Kidney Diseases, National Institutes of Health,

10 Center Drive, MSC 1453, CRC 5W-5940,

Bethesda, MD 20892, USA

e-mail: davidmh@mail.nih.gov

R. Chang $\cdot$ B. J. Wood $\cdot$ Z. Neeman $\cdot$ A. Kam

Diagnostic Radiology Department, Clinical Center,

National Institutes of Health,

Bethesda, MD, USA

R. A. Wesley

Office of the Director, Clinical Center,

National Institutes of Health,

Bethesda, MD, USA

S. M. Polly

Walter Reed Army Medical Center,

Washington, DC, USA

R. M. Hofmann

Department of Medicine, University of Wisconsin,

Madison, WI, USA transplant-based treatments of type 1 diabetes might promote recovery of native pancreatic beta cell function.

Methods We performed arginine stimulation tests in three islet transplant and four whole-pancreas transplant recipients, and measured stimulated C-peptide in select venous sampling sites. On the basis of each sampling site's C-peptide concentration and kinetics, we differentiated insulin secreted from the individual's native pancreatic beta cells and that secreted from allografted beta cells.

Results Selective venous sampling demonstrated that despite long-standing type 1 diabetes, all seven beta cell allograft recipients displayed evidence that their native pancreas secreted C-peptide. Yet even if chronic immunosuppression coupled with near normal glycaemia did improve native pancreatic $\mathrm{C}$ peptide production, the magnitude of the effect was quite small. Conclusions/interpretation Some native pancreatic beta cell function persists even years after disease onset in most type 1 diabetic patients. However, if prolonged euglycaemia plus anti-rejection immunosuppressive therapy improves native pancreatic insulin production, the effect in our participants was small. We may have underestimated pancreatic regenerative capacity by studying only a limited number of participants or by creating conditions (e.g. high circulating insulin concentrations or immunosuppressive agents toxic to beta cells) that impair beta cell function.

Trial registration ClinicalTrials.gov NCT00246844 and NCT00006505.

Keywords Beta cell regeneration · C-peptide · Islet transplantation $\cdot$ Pancreas transplantation $\cdot$ Type 1 diabetes 


\section{Abbreviation \\ NIH National Institutes of Health \\ SAS Selective arginine stimulation}

\section{Introduction}

Many basic and clinical studies support the hypothesis that pancreatic beta cells either survive in the long term or that the pancreas displays an under-appreciated capacity for beta cell functional recovery in patients with type 1 diabetes. Thus several studies have reported that a significant subset of people with type 1 diabetes continue to produce C-peptide for years after their diagnosis [1-7]. Other observations supporting persistent beta cell survival years after type 1 diabetes onset include: (1) older autopsy studies reporting anti-insulin antibody staining pancreatic cells [8-12]; (2) the high frequency (approaching 1\%) of HLA-restricted anti-insulin-specific $\mathrm{T}$ cells found in pancreas draining lymph nodes (the frequency of such anti-beta cell-specific $\mathrm{T}$ cells is much lower at other sites [13]), which suggests a higher insulin antigen concentration at that pancreatic lymph node site [14]; and (3) enduring anti-islet immune reactivity (anti-islet, anti-GAD and/or anti-insulinoma antigen 2 antibodies) [15-17]. The persistence of anti-beta cell-specific auto-antibodies is notable since patients with other autoimmune diseases (e.g. thyroid) typically lose their anti-tissue-specific antibodies after the target tissue is removed [18]. Collectively, these studies suggest that beta cells remain in the pancreas years after type 1 diabetes onset, despite continued evidence for an ongoing anti-beta cell immune response. Newer studies have expanded upon this earlier work reporting that a proportion of pancreatic beta cells undergo apoptosis or co-stain for markers of cell division (Ki67), suggesting a regular slow rate of beta cell loss and replacement $[19,20]$. Last, published and ongoing studies by several groups suggest that beta cell mass is regulated throughout life in humans, with diabetes perhaps representing an imbalance or failure of normal compensatory mechanisms [20-23].

Rodent studies, which allow for more rigorous controls, have shown that beta cell apoptosis and regeneration occur throughout life in mice and rats [24-28]. Other rodent studies suggest that controlling the anti-islet immune response can restore euglycaemia in rodents with autoimmune diabetes [29-32] and that beta cell proliferation is at least partially responsible for the effect [33].

Based upon these data, we asked whether ameliorating type 1 diabetes-associated metabolic abnormalities and the anti-beta cell autoimmunity might promote a measurable improvement in native pancreatic beta cell function in patients with the disease. Indeed, spontaneous recovery from apparent type 1 diabetes has been suggested [34].
Moreover, Japanese investigators have reported biopsy data from a single pancreas allograft recipient, suggesting that transplant-associated immunosuppression and euglycaemia may have promoted 'beta-like' cells to recover within the patient's native pancreas [35]. We therefore tested the hypothesis that chronic treatment of autoimmunity and hyperglycaemia might support the functional recovery of native pancreatic 'beta-like' cells. We measured native pancreatic C-peptide production in humans who had undergone beta cell replacement therapy either in the form of islet or whole-pancreas transplantation. In both instances, the patient's native pancreas is left in place when the allogeneic beta cells are transplanted. We discriminated between native pancreatic- and transplant-associated Cpeptide production using a novel 'selective arginine stimulation' (SAS) technique that takes advantage of the physical distance between the islet or whole-pancreas allograft and the recipient's native pancreas.

\section{Methods}

Enrolment All persons interested in participating in the National Institutes of Health (NIH) clinical islet transplantation protocol underwent C-peptide testing either at the $\mathrm{NIH}$ Clinical Center Chemistry Laboratory or in other Clinical Laboratory Improvement Amendments (CLIA)-approved referring hospitals or commercial laboratories. Patients who had undergone islet transplantation at the NIH between December 2000 and June 2001 were recruited to undergo venous sampling. Details of the islet transplant protocol and description of outcomes have been reported previously [36].

Patients with whole-organ allografts were recruited from major medical institutions that perform pancreas transplantation. To be eligible, participants had to: (1) have a clinical history consistent with type 1 diabetes prior to their transplant; (2) be 18 years of age or older; (3) have received a pancreas allograft with systemic (as opposed to portal) venous drainage at least 4 years earlier; (4) have had no rejection episodes for at least 1 year prior to this study using a stable immunosuppressive regimen; and (5) currently have insulin-independent euglycaemia. The need for the allograft to have venous anastomosis to either the inferior vena cava or the iliac vein (rather than the superior mesenteric vein, which drains via the portal vein to the liver) was of critical importance, since that state allowed cannulation from the femoral vein without transhepatic puncture and kept the pancreas allograft's venous effluent clearly distinct from the native pancreas venous outflow. Reasoning that native pancreatic beta cell regeneration may be a slow process, we limited our whole pancreas allograft recipient study to patients transplanted 4 years previously or more. 
All protocols were approved by the National Institute of Diabetes and Digestive and Kidney Diseases (NIDDK) Institutional Review Board and all procedures were performed after obtaining written informed consent. This research was supported by the Intramural Research Program of the NIH and NIDDK.

Patient evaluation and metabolic testing NIH islet transplant recipients (NCT00006505) received close clinical follow-up including frequent monitoring of immunosuppressant levels and arginine stimulation tests at three-monthly intervals prior to and through their enrolment in this venous sampling protocol (NCT00246844).

Whole-pancreas recipients who had received their allografts outside the NIH were admitted to the NIH Clinical Center for a complete history, physical examination, basic laboratory evaluation, a standard $2 \mathrm{~h} 75 \mathrm{~g}$ oral glucose tolerance test and standard peripheral arginine stimulation testing. Normal glucose tolerance was a prerequisite for participants to proceed with the sampling study.

C-peptide assays and routine arginine stimulation At the $\mathrm{NIH}, \mathrm{C}$-peptide concentrations were determined using one of two competitive chemiluminescence assays.

When participants were evaluated for transplant candidacy in 2000 and 2001, the Abbot Axsym assay (Abbott

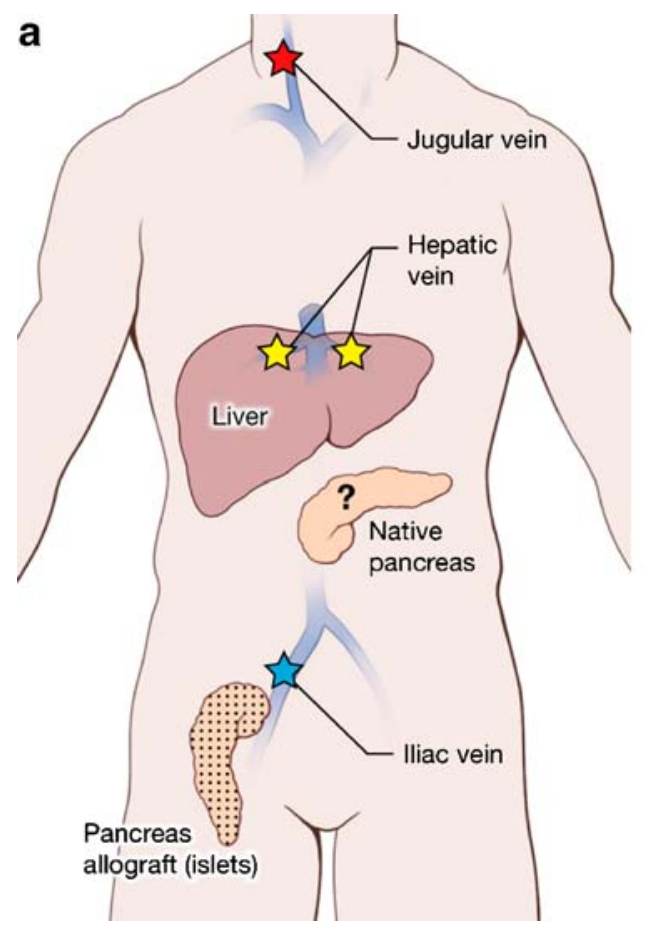

Fig. 1 Location of venous cannulas used for SAS. In the whole pancreas transplant patients (a), cannulas were placed in the hepatic (yellow stars), iliac (blue star) and jugular (red star) veins. Arginine stimulates both pancreases simultaneously. Any C-peptide produced by the native pancreas is detected in the hepatic veins before $\mathrm{C}$-peptide
Laboratories. Abbott Park, IL, USA) was used. Its lower limit of detection was $0.167 \mathrm{nmol} / 1$. The normal range for C-peptide in healthy individuals was $0.30-1.33 \mathrm{nmol} / \mathrm{l}$, with an intra-assay precision of $3.4 \%$ at $1.45 \mathrm{nmol} / 1$ and an inter-assay precision of $7.7 \%$ and $8.3 \%$ at $0.373 \mathrm{nmol} / 1$ and $1.98 \mathrm{nmol} / 1$ respectively.

For the SAS test C-peptide measurements, a more sensitive assay was available (Roche Elecsys reagents, F. Hoffmann-La Roche AG, Basel, Switzerland). The lower limit of detection was $0.0033 \mathrm{nmol} / 1$, the intra-assay precision was $1.3 \%$ and $2.6 \%$ at 0.105 and $0.0067 \mathrm{nmol} / 1$ respectively, with an interassay precision of $3.1 \%$ and $2.4 \%$ at $0.104 \mathrm{nmol} / 1$ and 0.007 nmol/l respectively.

Routine arginine stimulation tests were performed after an overnight fast by infusing $5 \mathrm{~g}$ of arginine hydrochloride $10 \%$ (wt/vol.) intravenously. Peripheral venous blood samples were drawn at time points: $-10,0,2,3,4,5,7$ and $10 \mathrm{~min}$ relative to the arginine injection [37].

Selective arginine stimulation Unlike the standard peripheral arginine stimulation test to detect an individual's Cpeptide response, the SAS test discriminates between the $\mathrm{C}$-peptide produced by the native pancreas and that produced by the transplanted allogeneic beta cells. The SAS technique exploits the fact that transplanted islets are placed in the recipient's liver and whole-pancreas allografts

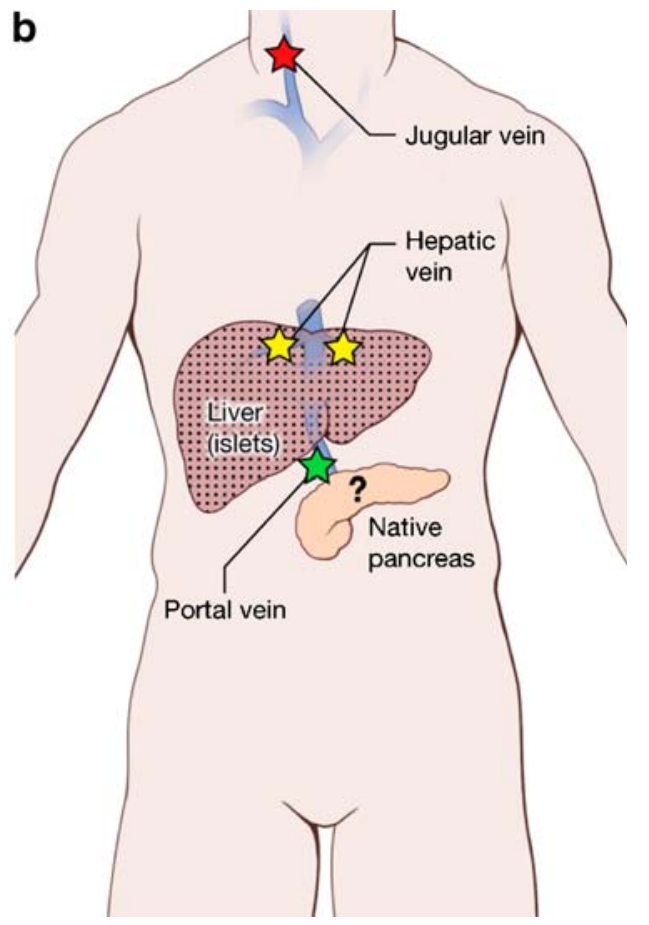

from the transplanted organ re-circulates (which would be detected by the jugular cannula). (b) In islet transplant patients, C-peptide found in the portal vein (green star) can be compared with the peripheral vein. Any early increase in the portal vein can be attributed to native pancreatic C-peptide production. Dots, transplanted beta cells 
in the pelvis, i.e. both are distant from the patient's native pancreas, which is not removed or altered during the transplant procedure. Thus, sampling blood immediately downstream from the different locations (liver, transplanted beta cells, native pancreas) after an arginine infusion identified the source of C-peptide secretion (Fig. 1). Assuming that arginine simultaneously reached the native pancreas and the allograft (islets or pancreas), we drew concurrent, sequential blood samples from the different venous sites (Fig. 1a, b). For islet transplant recipients, data interpretation was based on differences in C-peptide concentrations. Thus any C-peptide measured in the portal vein (over the simultaneously sampled peripheral vein site concentration) represented native pancreatic C-peptide production, while any C-peptide in the hepatic vein (over the simultaneously sampled portal vein concentration) represented islet allograft production. For whole-pancreas transplant recipients, data interpretation was based on Cpeptide kinetics such that, early after the arginine infusion, any $\mathrm{C}$-peptide concentration changes appearing in hepatic vein samples relative to simultaneously sampled peripheral vein samples represented native pancreas hormone production. We reasoned that any C-peptide produced by the transplanted pancreas would first have to travel through the systemic circulation before it could be detected, after that circulation time, in the cannula positioned in the hepatic vein.

All participants were admitted to the NIH Clinical Center for SAS. After an overnight fast with intravenous fluids, participants were taken to the interventional radiology suite and given conscious sedation with fentanyl $(50-100 \mu \mathrm{g})$ and midazolam (1-2 mg). Ultrasound and fluoroscopic guidance was employed to place catheters with multiple side-holes deep in the right and left hepatic veins (when possible) and in the left jugular vein. The hepatic veins were percutaneously accessed from the right and left jugular veins; the catheter's deep placement prevented any contamination from the inferior vena cava where C-peptide from the pancreas allograft would appear.

Means of gaining access to the veins just downstream from the allograft differed for whole-pancreas and isolated islet allograft recipients. For isolated islet transplant recipients, a transhepatic catheter was placed through the liver parenchyma into the portal vein. For pancreas transplant patients, a catheter was placed via the ipsilateral femoral vein into the allograft's venous anastomosis.

After all cannula placements had been confirmed, and with the patient remaining in the interventional radiology suite, $5 \mathrm{~g}$ of arginine $10 \%(\mathrm{wt} / \mathrm{vol}$.) was injected over $30 \mathrm{~s}$ through a peripheral vein and blood (approximately $2 \mathrm{ml}$ per sample) was drawn from each site simultaneously up to every $10 \mathrm{~s}$. The catheters were not flushed between samples and deadspace for each cannula was similar (less than $1.0 \mathrm{ml}$ ). After all samples were collected, cannulas were removed and haemostasis achieved by applying local pressure. Serum was separated from the samples after centrifugation for $20 \mathrm{~min}$ at $900 \mathrm{~g}$ and $4^{\circ} \mathrm{C}$, and C-peptide concentrations were determined by the NIH Clinical Center laboratory.

Data analysis For patients presenting for possible enrolment in the islet transplant protocol, we evaluated various clinical variables for an association with measurable C-peptide concentrations greater than $0.167 \mathrm{nmol} / 1 \mathrm{l}$ using either unpaired Student's $t$ or Fisher's exact tests at a significance level of $p<0.05$. Bonferroni correction was applied for multiple comparisons. We determined the source of any measured C-peptide as described above. For the beta cell allograft recipients, we reasoned that if the native pancreas made no C-peptide, then the C-peptide concentration in blood sampled downstream of that pancreas should be the same as that in blood sampled simultaneously from a central or peripheral venous site. In such a scenario, C-peptide concentrations downstream from the native pancreas should be greater than simultaneously sampled peripheral vein concentrations only $50 \%$ of the time (i.e. pure chance). We applied standard binomial probability testing (akin to the probability test applied to coin tosses) to assess the probability of C-peptide concentrations downstream of the native pancreas being greater than simultaneously sampled peripheral vein concentrations.

\section{Results}

C-peptide in a general population with type 1 diabetes $\mathrm{C}$ peptide values were assessed in 141 potential participants for the islet transplant protocol. In total, 104 measurements were performed by the NIH Clinical Center and 37 by outside centres. Consistent with previous reports, 38 of the 141 patients $(27 \%)$ had detectable C-peptide concentrations $\geq 0.167 \mathrm{nmol} / \mathrm{l}$. Of the 103 patients with $\mathrm{C}$-peptide concentration $\leq 0.167 \mathrm{nmol} / 1,51$ underwent standard arginine stimulation testing. An additional 16 patients were found to have C-peptide concentrations of $\geq 0.167 \mathrm{nmol} / 1$. Thus, the incidence of a positive arginine test result in patients without measurable basal levels was $16 / 51$ (31.4\%), consistent with other reports showing C-peptide responses following a glucagon-challenge in $23 \%$ of 105 patients with long-standing type 1 diabetes [17]. All together, at least 54 of the 141 patients evaluated (38.3\%) had either basal or arginine-stimulated C-peptide levels of at least $0.167 \mathrm{nmol} / 1$.

We analysed multiple clinical variables to find potential patient characteristics associated with detectable C-peptide (Table 1). Only disease duration achieved apparent statistical significance. Those patients with detectable C-peptide had a disease duration of $19.2 \pm 11.8$ years vs $26.2 \pm 13.1$ years for those without detectable C-peptide $(p=0.004)$. However, 
Table 1 Clinical variables that were tested in participants with C-peptide production in random serum samples

\begin{tabular}{|c|c|c|c|}
\hline & Positive for C-peptide & Negative for C-peptide & $p$ value \\
\hline Participants, total $(n)$ & 38 & 103 & \\
\hline Participants, women $(n)$ & 24 & 59 & 0.57 \\
\hline BMI $\left(\mathrm{kg} / \mathrm{m}^{2}\right)$ & $25.0(3.78)$ & $24.5(3.35)$ & 0.41 \\
\hline Age of diabetes onset (years) & $16.7(10.6)$ & $16.7(9.90)$ & 0.98 \\
\hline Diabetes duration (years) & $19.2(11.8)$ & $26.2(13.1)$ & 0.0045 \\
\hline $\mathrm{HbA}_{1 \mathrm{c}}(\%)$ & $8.19(2.27)$ & $7.95(1.42)$ & 0.45 \\
\hline Anti-GAD antibody-positive (\%) & 61.9 & 63.9 & 1.00 \\
\hline LDL-cholesterol (mmol/l) & $2.87(0.817)$ & $2.90(0.732)$ & 0.89 \\
\hline HDL-cholesterol (mmol/l) & $1.71(0.546)$ & $63.5(0.440)$ & 0.51 \\
\hline Triacylglycerol $(\mathrm{mmol} / \mathrm{l})$ & $1.05(0.641)$ & $0.920(0.586)$ & 0.29 \\
\hline Current insulin pump use (\%) & 39.5 & 37.9 & 0.85 \\
\hline DKA episodes (lifetime) & $3.59(6.79)$ & $3.72(11.4)$ & 0.95 \\
\hline Blood glucose for hypoglycaemia symptoms (mmol/l) & $3.04(0.967)$ & $2.88(0.883)$ & 0.41 \\
\hline Nephropathy (\%) & 50.0 & 40.2 & 0.34 \\
\hline Neuropathy $(\%)$ & 42.1 & 35.3 & 0.56 \\
\hline Retinopathy (\%) & 57.9 & 57.8 & 1.00 \\
\hline
\end{tabular}

Unless otherwise stated, data are presented as means (SD)

DKA, clinically diagnosed and patient-reported diabetic ketoacidosis

after Bonferroni correction for the 15 variables studied, the $p$ value of disease duration was not less than the corrected $\alpha$ value of 0.003 and cannot therefore be considered statistically significant.

We next sought to assess whether any of the measured circulating C-peptide was secreted from the patient's pancreas since non-pancreatic insulin synthesis has been reported [38-40]

SAS in islet allograft recipients Three patients with successful islet transplantation clinical outcomes (i.e. insulinindependent euglycaemia for at least 1 year following the procedures) agreed to undergo SAS (Table 2). Importantly, none of the three had measurable peripheral vein $\mathrm{C}$-peptide concentrations (basal or stimulated) of at least $0.167 \mathrm{nmol} /$ 1 prior to receiving their isolated islet allograft. Patients 1 and 2 were both insulin-independent at the time of the SAS procedure. Both underwent this procedure more than 2 years after their last islet allograft infusion and, as per protocol, were maintained on their immunosuppressive medications (tacrolimus and sirolimus). Patient 3 was studied several months after discontinuing all immunosuppressive agents due to complications related to immunosuppressive agents [41] and at the time of the SAS procedure had returned to her pretransplant injected insulin requirements.

C-peptide concentrations measured in the portal vein of the first insulin-independent patient were consistently higher than those simultaneously sampled from the patient's peripheral vein site during the first 5 min after the arginine injection (Table 3, Fig. 2a). The second insulin-independent islet recipient (patient 2) showed no obvious difference (Table 3, Fig. 2b) in the C-peptide concentrations measured in the portal and peripheral vein samples. Even so, we noted that five of the six C-peptide concentrations measured in the patient's portal vein within the first $60 \mathrm{~s}$ following arginine infusion were slightly higher than simultaneously measured peripheral vein concentrations. The probability of that happening by chance, using binomial probabilities, is $p=0.094$ suggesting some potential native pancreatic C-peptide production. The third islet transplant recipient, studied 11 months after discontinuing all immunosuppression (patient 3) [41], also displayed a consistent 'step-up' in portal vein compared with simultaneously sampled peripheral vein C-peptide concentrations, although the C-peptide concentrations were very low (Table 3 ). Again, while the magnitude of the 'step-up' in Patient 3 was extremely small, it was persistent in 10 of 12 samples taken from 10 to $300 \mathrm{~s}$ post-arginine injection (binomial probabilities $p=0.016$ ). We reasoned from these data that at least two and perhaps all three islet allograft recipients displayed evidence of native pancreatic C-peptide production. We therefore sought to study successful pancreas allograft recipients to determine whether longer term (at least 4 years) immunosuppression and euglycaemia might promote clinically significant native pancreatic insulin production.

SAS in whole-pancreas allograft recipients All four wholepancreas allograft recipients had also received a concurrent kidney allograft due to type 1 diabetes-associated kidney 


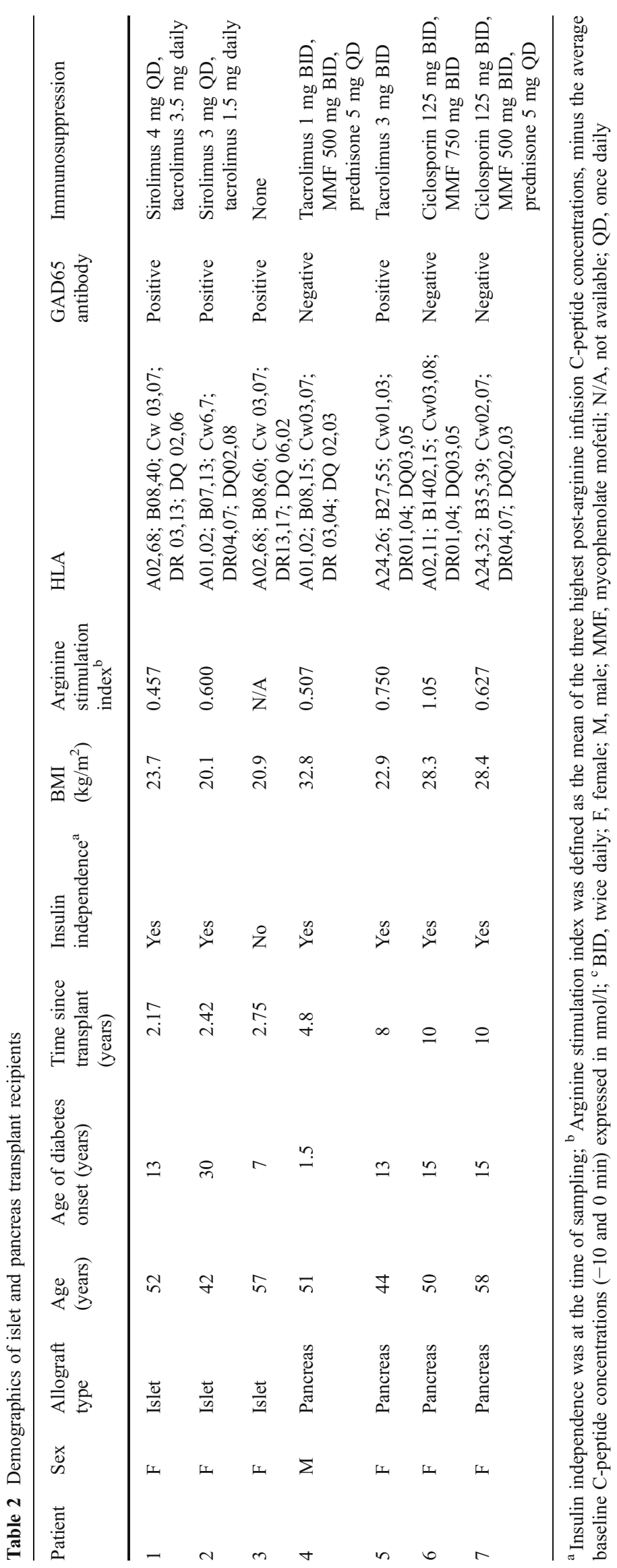



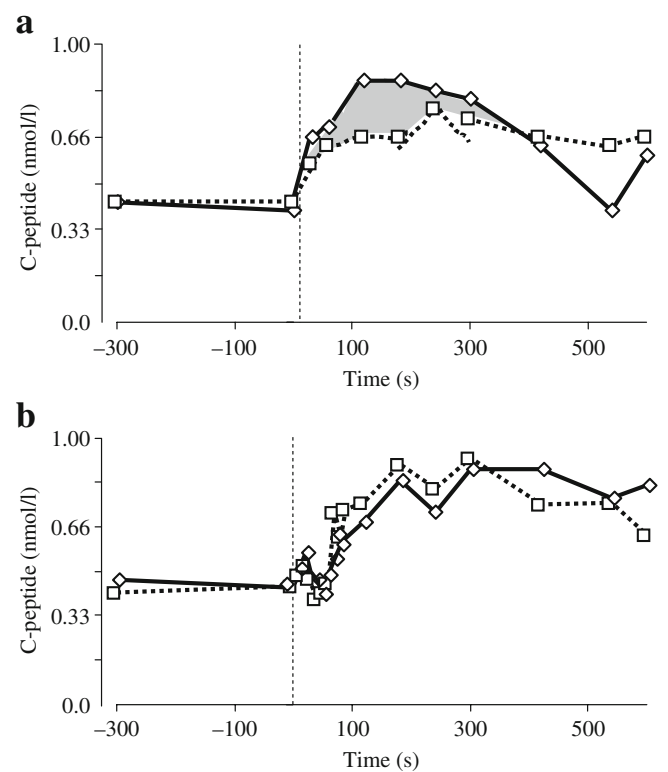

Fig. 2 Stimulated C-peptide responses in two insulin-independent recipients of isolated islet allografts. (a) Patient 1 displayed a significant 'step-up' in portal vein (diamonds) C-peptide concentrations. Grey shading shows excess portal vein C-peptide concentration relative to simultaneously sampled peripheral vein (squares) samples. (b) Patient 2 had nearly identical C-peptide concentrations at all time points. Dotted vertical line, time point of arginine infusion

failure (Table 2). All had been diagnosed with type 1 diabetes during childhood and were continuously treated with insulin from the time of diagnosis until their pancreas transplant. Unfortunately, their C-peptide secretion had not been tested prior to the simultaneous pancreas-kidney transplantation. Post transplant, all participants had insulin-independent euglycaemia, as documented by normal $\mathrm{HbA}_{1 \mathrm{C}}$ values. Immunosuppression to prevent allograft rejection consisted of chronic calcineurin inhibitor use (tacrolimus or ciclosporin) in conjunction with either mycophenolate mofetil or low-dose glucocorticoid.

Each pancreas allograft recipient displayed normal glucose tolerance (data not shown) and robust arginine stimulation indices consistent with the strong allograft Cpeptide signal during SAS (Fig. 3). As shown in Table 3 and Fig. 3, the allograft venous samples (measured in the iliac vein) showed rapid C-peptide secretion within 20 to $30 \mathrm{~s}$ after initiating the arginine infusion with peak concentrations $(27.3$ to $183 \mathrm{nmol} / \mathrm{l})$ reached within $50 \mathrm{~s}$. Peripheral vein C-peptide concentrations (measured in the jugular vein) increased approximately 60 to $90 \mathrm{~s}$ after arginine infusion and were much lower (owing to dilution in the peripheral circulation). Therefore, we interpreted any $\mathrm{C}$-peptide measured in the hepatic veins (which drain the native pancreas) within the first $60 \mathrm{~s}$ after arginine infusion to reflect hormone produced in the native pancreas (see Fig. 1).
Because of a small left liver lobe with no easily accessible left hepatic vein (a normal anatomical variation) in Patient 4 (Table 3, Figs 3a and 4a), we were able to measure only the right hepatic vein C-peptide concentrations. Allograft-produced C-peptide became detectable in the jugular vein $60 \mathrm{~s}$ after the arginine infusion, then in the hepatic vein $90 \mathrm{~s}$ after the arginine infusion. However, within $30 \mathrm{~s}$ following the arginine injection, a transient $\mathrm{C}$ peptide increase was measured in the hepatic vein. We interpret this result as representing native pancreatic Cpeptide production (i.e. $1.27 \mathrm{nmol} / \mathrm{l}$ in the jugular vein compared with $1.70 \mathrm{nmol} / \mathrm{l}$ in the hepatic vein blood).

For Patients 5, 6 and 7 (Table 3, Figs. 3b-d and 4b-d), cannulae were successfully placed in both right and left hepatic veins. Mean hepatic C-peptide levels were consistently elevated over peripheral levels in these patients, but only marginally so $(<7 \%$ increase in all patients between times $10-50 \mathrm{~s}$ ). While the absolute hepatic vein C-peptide concentrations were only slightly higher than the simultaneously sampled central vein concentrations, 14 of 18 relevant time-points sampled within the first minute following the arginine infusion showed higher C-peptide concentrations in the hepatic vein samples (binomial probabilities $p=0.01$ ). Even so, the difference between the two areas under the curve (for the first $60 \mathrm{~s}$ following the arginine infusion) was only $1.05,1.35$ and $2.28 \mathrm{nmol} \mathrm{s}^{-1} \mathrm{ml}^{-1}$, respectively for the three patients. Interestingly, Patient 5 rejected her pancreas allograft 3 months after sampling and returned to complete insulin dependence. Taking all four pancreas allograft recipient data into account, hepatic vein C-peptide concentrations were greater than simultaneously sampled peripheral vein concentrations in 17 of the 24 comparisons within the first $60 \mathrm{~s}$ following arginine infusion (binomial probability $p=0.021$ ) (Table 3). Taking all seven beta cell allograft recipient data into account (i.e. combining data from the isolated islet and whole-pancreas recipients), C-peptide concentrations measured downstream of the native pancreas were greater than simultaneously sampled peripheral vein concentrations in 29 of the 38 comparisons within the first $60 \mathrm{~s}$ following arginine infusion (binomial probability $p=0.00059)$ (Table 3).

\section{Discussion}

Diabetes therapy would be revolutionised by any intervention that promotes growth of functional beta cells in the pancreas of a patient with type 1 diabetes. We thus sought to test: (1) whether insulin secretion persists in a convincing number of persons with long-standing type 1 diabetes; and if so (2) whether modulating autoimmunity and controlling the metabolic milieu might support beta cell functional recovery. We found that 38 of the $141(27 \%)$ patients with 


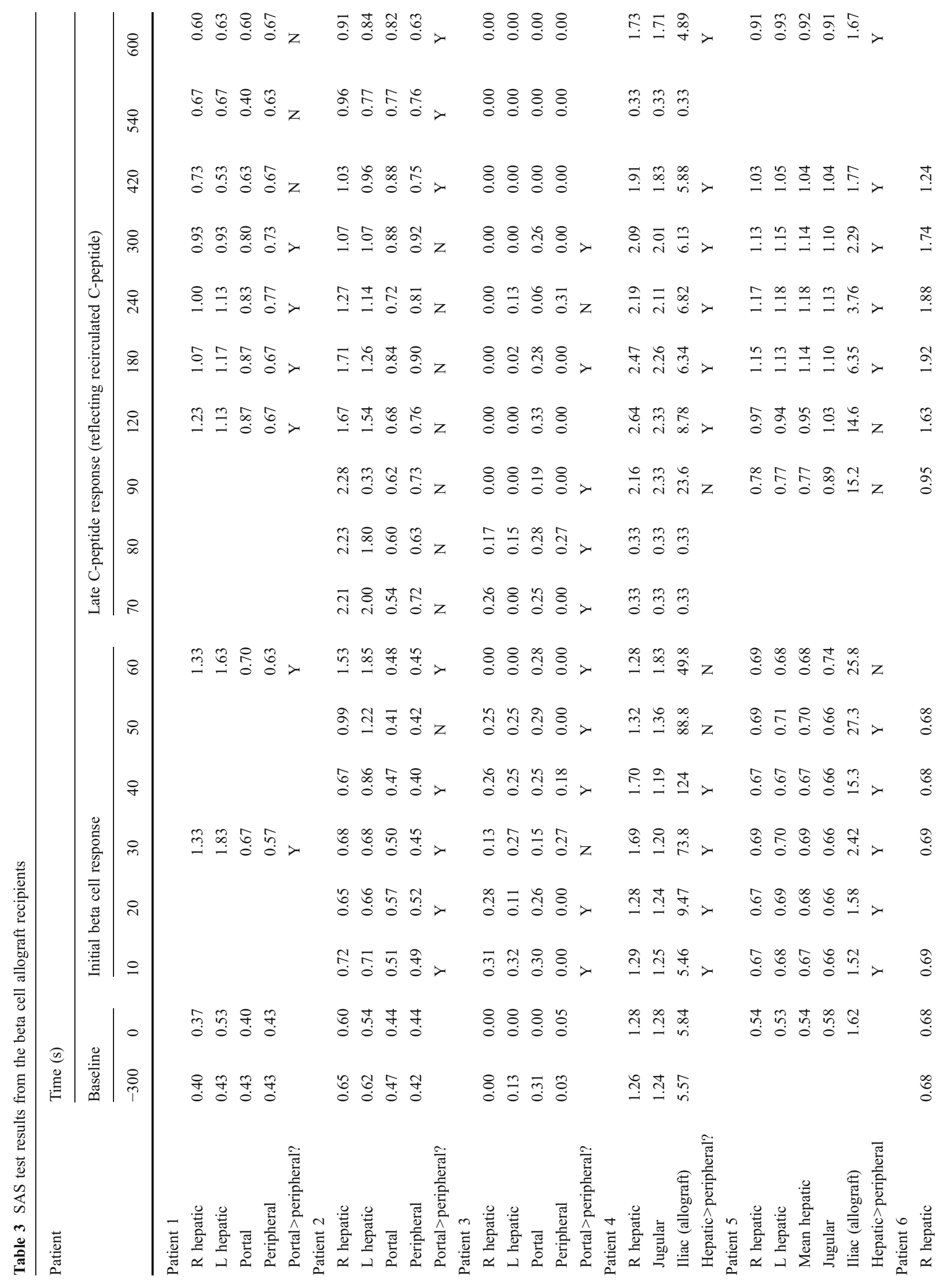




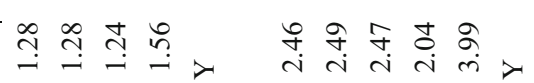

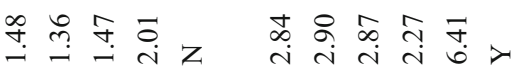

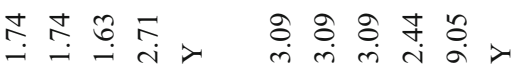

के

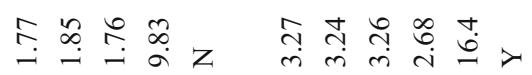

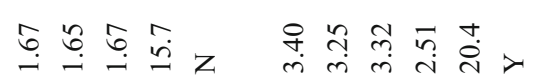

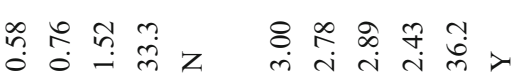

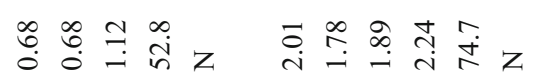

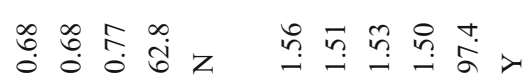

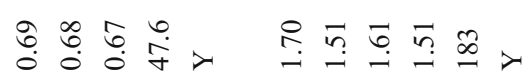

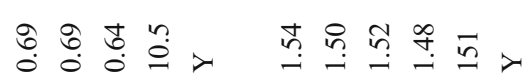

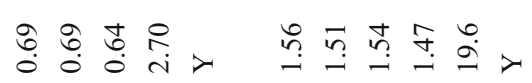

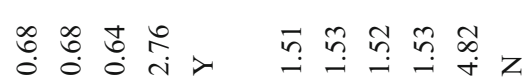

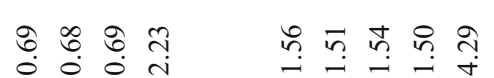

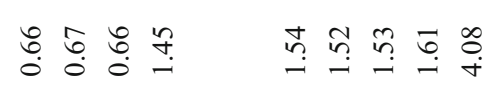

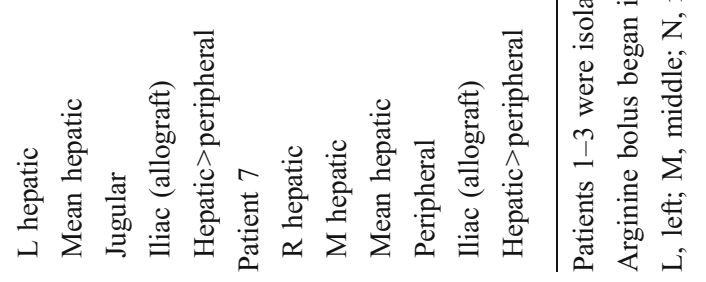


a

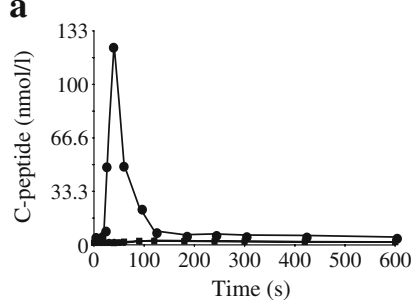

c

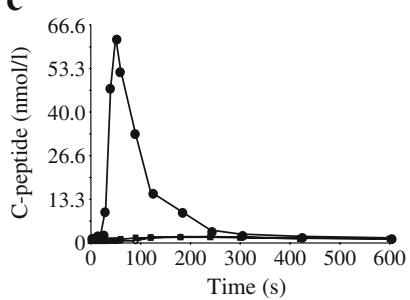

b

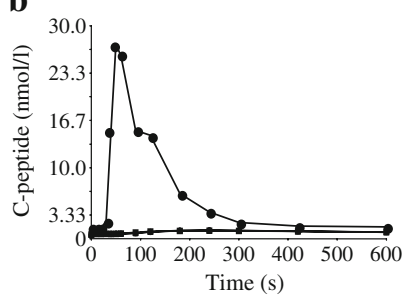

d

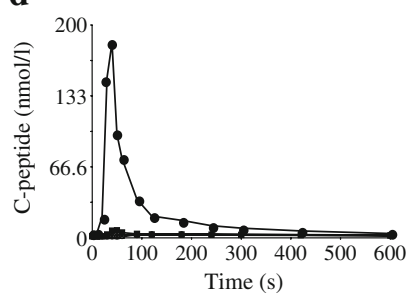

Fig. 3 C-peptide results from all sampling sites in pancreas allograft patients 4 (a), 5 (b), 6 (c) and 7 (d) showing that most of the circulating C-peptide originated from the allograft. Circles show iliac vein samples (venous effluent from the pancreas allograft), while $\mathrm{C}$ peptide concentrations measured from the other sites (hepatic and jugular) and appear superimposed below the iliac sample concentrations (squares). A closer view of the C-peptide concentrations from the hepatic and jugular veins from these patients is shown in Fig. 4

long-term type 1 diabetes had random C-peptide concentrations of at least $0.167 \mathrm{nmol} / \mathrm{l}$ and that another third (16 of 51) with random circulating C-peptide concentrations less than $0.167 \mathrm{nmol} / 1$ could still produce C-peptide of at least $0.167 \mathrm{nmol} / 1$ following arginine stimulation. Overall, these data suggest that pancreatic insulin function persists in over a third of individuals with long-standing type 1 diabetes, but is minimal and often detectable only after appropriate stimulation and with sensitive C-peptide assays.

The endogenous insulin secretion observed in patients with long-standing type 1 diabetes is consistent with previous reports [2-7] and prompted us to look for native pancreas beta cell regeneration in islet transplant recipients. Having found evidence for some native pancreas C-peptide production following several months of euglycaemia and immunosuppression in at least two and possibly all three islet allograft recipients, we evaluated patients with longer term beta cell replacement and immunosuppression. Using the SAS method, which discriminates between native and allograft C-peptide production, patients with wholepancreas allografts offered a unique opportunity to test the possibility. We hypothesised that long-term treatment for autoimmunity and beta cell failure would provide the best environment for native islet recovery. However, our results do not support the notion that robust recovery of beta cell function occurs in these individuals. In total, while all seven beta cell allograft recipients displayed slightly higher Cpeptide concentrations in the native pancreatic venous effluent than in simultaneously sampled peripheral vein

blood, the concentration gradient was very small and we cannot state definitively that the gradient improved relative to what may have been measured pre-transplant; we also saw no clear dose-response relationship. Thus despite more than 8 years of immunosuppression and metabolic control enjoyed by whole-pancreas allograft recipients 5, 6 and 7, the $\mathrm{C}$-peptide produced by their native pancreas was mimimal.

While these data are provocative, we recognise several limitations. For instance, our estimates regarding the proportion of individuals with long-standing type 1 diabetes with continued C-peptide production (even though the participants met established clinical type 1 diabetes diagnostic criteria) may have been biased by the participants' referral for research protocol participation (e.g. such patients may treat their diabetes differently). Furthermore, our attempt to correlate clinical characteristics with detectable C-peptide may not have encompassed relevant variables during screening (e.g. HLA type) or might require a larger patient population because of the weak association. Also, several studies have reported that cells other than those in the pancreas can produce insulin under certain circumstances, so the C-peptide may not be a product of residual pancreatic beta cells [38-40], although data presented herein suggests that at least some of that C-peptide was indeed produced by the pancreas.

Additional caveats with regard to our allograft studies include the fact that we studied a limited number of
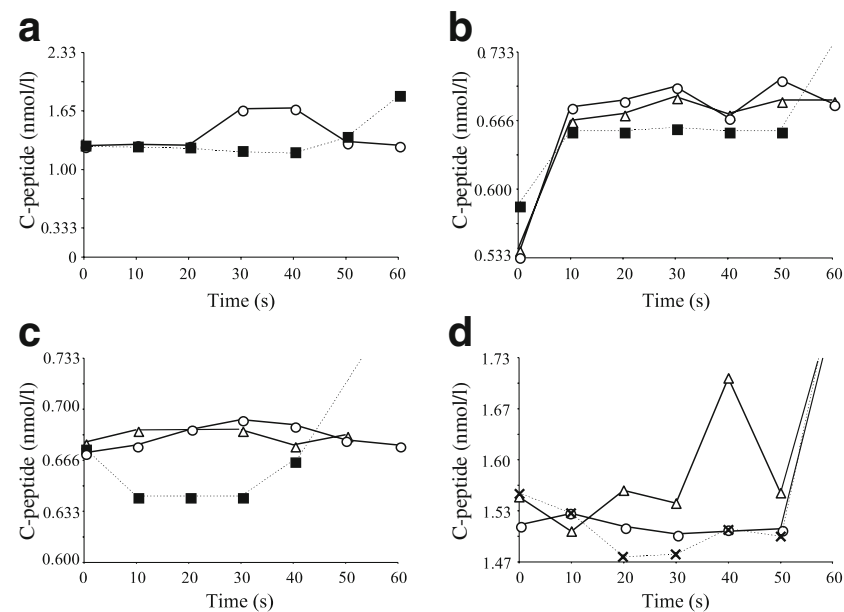

Fig. 4 C-peptide concentration from the hepatic and peripheral sampling sites (excluding the pancreas allograft iliac vein results shown in Fig. 3) in pancreas allograft patients 4 (a), 5 (b), 6 (c) and 7 (d) early after the arginine infusion. Each patient displays transient, minimally elevated level C-peptide concentrations when hepatic vein samples are compared with concurrent peripheral vein blood samples. Circles, left hepatic (except patient 7 shown in (d) where the circles represent middle hepatic); triangles, right hepatic; squares, jugular; crosses (patient 7 shown in d), peripheral 
participants. So while we can conclude that native pancreas does not commonly 'heal' to produce very much C-peptide following a successful beta cell allograft (and associated chronic immunosuppression and controlled metabolic variables), occasional recovery cannot be ruled out. It is also possible that patients with more advanced diabetes complications (each of the patients we studied had longstanding type 1 diabetes prior to their transplant) might have a reduced beta cell regenerative capacity. Furthermore, we looked for native pancreatic beta cell function by using arginine to stimulate insulin and C-peptide release. While arginine stimulation is known to produce a strong and rapid secretory response from normal native and allograft pancreases [42], 'regenerated' or immature native pancreatic beta cells may not respond to such a stimulus [43]. In addition, careful follow-up of our islet allograft recipients has documented that exogenous insulin can diminish in vivo islet secretory responses to arginine (KI Rother and DM Harlan, unpublished observation). Thus, the supraphysiological circulating insulin concentrations typically found in pancreas allograft recipients, and in particular those with systemically drained pancreas allografts, may have suppressed the native pancreatic beta cell regenerative response. Another consideration is that mild hyperglycaemia may be an important stimulant for beta cell regeneration or recovery. Animal studies suggest that glucose sensing through glucokinase and insulin receptor substrate-2 may be important for compensatory beta cell hyperplasia $[33,44]$. It is possible that good, but imperfect glucose control can stimulate beta cell growth and account for the persistent C-peptide levels found in patients with long standing type 1 diabetes. Finally, current immunosuppressive regimens (relying upon calcineurin inhibitors, anti-metabolites and glucocorticoids) may have directly prevented native pancreatic beta cell regeneration. Of the four pancreas transplant patients, the one with the strongest response (Patient 4) also had the shortest exposure to calcineurin inhibitor therapy (4.5 years). Animal data support this observation. For instance, recent rodent studies suggest that calcineurin/nuclear factor of activated $\mathrm{T}$ cells signal blockade prevents beta cell growth and function [45]. Also, since the effectiveness of these immunosuppressive agents for autoimmunity is poorly understood, chronic insulitis may still be inhibiting beta cell regeneration [46, 47]. If so, then therapies directed towards beta cell regeneration, beta cell replacement or beta cell repopulation will require new and less toxic immunosuppressive regimens [48].

Our present study suggests that vigorous beta cell regeneration does not occur in patients with long-term type 1 diabetes after islet or pancreas transplantation. While beta cell regeneration cannot be completely ruled out, these data suggest that the process is not robust given allograft-mediated restoration of glucose metabolism and currently available immunosuppression designed to abrogate the auto-and alloimmune processes. The C-peptide assays performed by most clinical departments employ kits that detect C-peptide levels at or near the normal range, i.e. with lower limits of detection of $0.167 \mathrm{nmol} / \mathrm{l}$, while the normal range for C-peptide in healthy individuals is $0.30-1.33 \mathrm{nmol} / 1$. Using these standard assays, very low basal C-peptide levels are often not detected and therefore any pancreatic islet regeneration restoring C-peptide production to low but perhaps still significant levels will not be observed. Future studies aimed at restoring pancreas function should always use more sensitive C-peptide assays. Therapies using other methods of immunosuppression (e.g. calcineurin inhibitor and steroid sparing) and agents to stimulate beta cell replication may yet still prove successful.

Acknowledgements The authors would like to thank J. Jesson for her help in the pancreas transplant sampling protocol. We also would like to thank P. Swanson and T. Wakefield for their help in protocol preparation and management, and J. Lee, F. Leopardi and P. Brooks for their assistance in obtaining and processing of samples. This research was supported by the Intramural Research Program of the NIDDK/NIH and the Clinical Center/NIH.

Duality of interest The authors declare that there is no duality of interest associated with this manuscript.

\section{References}

1. No authors listed (1998) Effect of intensive therapy on residual beta-cell function in patients with type 1 diabetes in the diabetes control and complications trial. A randomized, controlled trial. The Diabetes Control and Complications Trial Research Group. Ann Intern Med 128:517-523

2. Madsbad S (1983) Factors of importance for residual beta-cell function in type I diabetes mellitus. A review. Acta Med Scand Suppl 671:61-67

3. Madsbad S, Faber OK, Binder C et al (1978) Prevalence of residual beta-cell function in insulin-dependent diabetics in relation to age at onset and duration of diabetes. Diabetes 27 (Suppl 1):262-264

4. Eff C, Faber O, Deckert T (1978) Persistent insulin secretion, assessed by plasma C-peptide estimation in long-term juvenile diabetics with a low insulin requirement. Diabetologia 15:169-172

5. Scholin A, Bjorklund L, Borg $\mathrm{H}$ et al (2004) Islet antibodies and remaining beta-cell function 8 years after diagnosis of diabetes in young adults: a prospective follow-up of the nationwide Diabetes Incidence Study in Sweden. J Intern Med 255:384-391

6. Steffes MW, Sibley S, Jackson M, Thomas W (2003) Beta-cell function and the development of diabetes-related complications in the diabetes control and complications trial. Diabetes Care 26:832836

7. Madsbad S (1983) Prevalence of residual B cell function and its metabolic consequences in type 1 (insulin-dependent) diabetes. Diabetologia 24:141-147

8. Gepts W, de Mey J (1978) Islet cell survival determined by morphology. An immunocytochemical study of the islets of Langerhans in juvenile diabetes mellitus. Diabetes 27(Suppl 1):251261 
9. Stefan Y, Orci L, Malaisse-Lagae F et al (1982) Quantitation of endocrine cell content in the pancreas of nondiabetic and diabetic humans. Diabetes 31:694-700

10. Lohr M, Kloppel G (1987) Residual insulin positivity and pancreatic atrophy in relation to duration of chronic type 1 (insulin-dependent) diabetes mellitus and microangiopathy. Diabetologia 30:757-762

11. Foulis AK, Liddle CN, Farquharson MA et al (1986) The histopathology of the pancreas in type 1 (insulin-dependent) diabetes mellitus: a 25-year review of deaths in patients under 20 years of age in the United Kingdom. Diabetologia 29:267-274

12. Gepts W (1984) Islet morphology in type I diabetes. Behring Inst Mitt 75:39-41

13. Pinkse GG, Tysma OH, Bergen CA et al (2005) Autoreactive CD8 $\mathrm{T}$ cells associated with beta cell destruction in type 1 diabetes. Proc Natl Acad Sci U S A 102:18425-18430

14. Kent SC, Chen Y, Bregoli L et al (2005) Expanded T cells from pancreatic lymph nodes of type 1 diabetic subjects recognize an insulin epitope. Nature 435:224-228

15. Yokota I, Matsuda J, Naito E et al (1998) Comparison of GAD and ICA512/IA-2 antibodies at and after the onset of IDDM. Diabetes Care 21:49-52

16. Simone E, Eisenbarth GS (1996) Chronic autoimmunity of type I diabetes. Horm Metab Res 28:332-336

17. Jaeger C, Allendorfer J, Hatziagelaki E et al (1997) Persistent GAD 65 antibodies in longstanding IDDM are not associated with residual beta-cell function, neuropathy or HLA-DR status. Horm Metab Res 29:510-515

18. Chiovato L, Latrofa F, Braverman LE et al (2003) Disappearance of humoral thyroid autoimmunity after complete removal of thyroid antigens. Ann Intern Med 139:346-351

19. Meier JJ, Butler AE, Saisho Y et al (2008) Beta-cell replication is the primary mechanism subserving the postnatal expansion of beta-cell mass in humans. Diabetes 57:1584-1594

20. Meier JJ, Bhushan A, Butler AE et al (2005) Sustained beta cell apoptosis in patients with long-standing type 1 diabetes: indirect evidence for islet regeneration? Diabetologia 48:2221-2228

21. Butler AE, Janson J, Bonner-Weir S et al (2003) Beta-cell deficit and increased beta-cell apoptosis in humans with type 2 diabetes. Diabetes 52:102-110

22. Meier JJ, Lin JC, Butler AE et al (2006) Direct evidence of attempted beta cell regeneration in an 89-year-old patient with recent-onset type 1 diabetes. Diabetologia 49:1838-1844

23. Yoon KH, Ko SH, Cho JH et al (2003) Selective beta-cell loss and alpha-cell expansion in patients with type 2 diabetes mellitus in Korea. J Clin Endocrinol Metab 88:2300-2308

24. Teta M, Rankin MM, Long SY et al (2007) Growth and regeneration of adult beta cells does not involve specialized progenitors. Dev Cell 12:817-826

25. Kushner JA (2006) Beta-cell growth: an unusual paradigm of organogenesis that is cyclin D2/Cdk4 dependent. Cell Cycle 5:234-237

26. Teta M, Long SY, Wartschow LM et al (2005) Very slow turnover of beta-cells in aged adult mice. Diabetes 54:2557-2567

27. Bonner-Weir S (2001) Beta-cell turnover: its assessment and implications. Diabetes 50(Suppl 1):S20-S24

28. Bonner-Weir S (2000) Islet growth and development in the adult. J Mol Endocrinol 24:297-302

29. Sherry NA, Kushner JA, Glandt M et al (2006) Effects of autoimmunity and immune therapy on beta-cell turnover in type 1 diabetes. Diabetes 55:3238-3245

30. Zorina TD, Subbotin VM, Bertera S et al (2003) Recovery of the endogenous beta cell function in the NOD model of autoimmune diabetes. Stem Cells 21:377-388
31. von Herrath MG, Wolfe T, Mohrle U et al (2001) Protection from type 1 diabetes in the face of high levels of activated autoaggressive lymphocytes in a viral transgenic mouse model crossed to the SV129 strain. Diabetes 50:2700-2708

32. Ryu S, Kodama S, Ryu K et al (2001) Reversal of established autoimmune diabetes by restoration of endogenous beta cell function. J Clin Invest 108:63-72

33. Pechhold K, Koczwara K, Zhu X et al (2009) Blood glucose levels regulate pancreatic beta-cell proliferation during experimentally-induced and spontaneous autoimmune diabetes in mice. PLoS ONE 4(3):e4827

34. Karges B, Durinovic-Bello I, Heinze E et al (2004) Complete long-term recovery of beta-cell function in autoimmune type 1 diabetes after insulin treatment. Diabetes Care 27:12071208

35. Kuroda A, Yamasaki Y, Imagawa A (2003) Beta-cell regeneration in a patient with type 1 diabetes mellitus who was receiving immunosuppressive therapy. Ann Intern Med 139:W81

36. Hirshberg B, Rother KI, Digon BJ et al (2003) Solitary islet transplantation for type 1 diabetes mellitus using steroid sparing immunosuppression: The NIH experience. Diabetes Care 26:3288-3295

37. Teuscher AU, Kendall DM, Smets YF et al (1998) Successful islet autotransplantation in humans: functional insulin secretory reserve as an estimate of surviving islet cell mass. Diabetes 47:324-330

38. Pugliese A, Zeller M, Fernandez A Jr et al (1997) The insulin gene is transcribed in the human thymus and transcription levels correlated with allelic variation at the INS VNTRIDDM2 susceptibility locus for type 1 diabetes. Nat Genet 15:293-297

39. Narendran P, Neale AM, Lee BH et al (2006) Proinsulin is encoded by an RNA splice variant in human blood myeloid cells. Proc Natl Acad Sci U S A 103:16430-16435

40. Kojima H, Fujimiya M, Matsumura K et al (2004) Extrapancreatic insulin-producing cells in multiple organs in diabetes. Proc Natl Acad Sci U S A 101:2458-2463

41. Digon BJ III, Rother KI, Hirshberg B, Harlan DM (2003) Sirolimus-induced interstitial pneumonitis in an islet transplant recipient. Diabetes Care 26:3191

42. Ganda OP, Srikanta S, Brink SJ et al (1984) Differential sensitivity to beta-cell secretagogues in "early" type I diabetes mellitus. Diabetes 33:516-521

43. D'Amour KA, Bang AG, Eliazer S et al (2006) Production of pancreatic hormone-expressing endocrine cells from human embryonic stem cells. Nat Biotechnol 24:1392-1401

44. Terauchi Y, Takamoto I, Kubota N et al (2007) Glucokinase and IRS-2 are required for compensatory beta cell hyperplasia in response to high-fat diet-induced insulin resistance. J Clin Invest 117:246-257

45. Heit JJ, Apelqvist AA, Gu X et al (2006) Calcineurin/NFAT signalling regulates pancreatic beta-cell growth and function. Nature 443:345-349

46. Meier JJ, Ritzel RA, Maedler K et al (2006) Increased vulnerability of newly forming beta cells to cytokine-induced cell death. Diabetologia 49:83-89

47. Zhang C, Todorov I, Lin CL et al (2007) Elimination of insulitis and augmentation of islet beta cell regeneration via induction of chimerism in overtly diabetic NOD mice. Proc Natl Acad Sci U S A 104:23372342

48. Liu EH, Siegel RM, Harlan DM, O'Shea JJ (2007) T cell-directed therapies: lessons learned and future prospects. Nat Immunol $8: 25-30$ 